\title{
Investigating the key drivers of traveler loyalty in the airport lounge setting
}

\begin{abstract}
This study intended to examine the structural relationships among functional congruity factors, delight, well-being perception, brand identification, and traveler satisfaction in the formation of air traveler loyalty for airline lounges. The survey sample consisted of 394 air travelers who visited an airline lounge in airport in the U.S. during the past six months. Structural equation modeling was used to test the conceptual model. Results of the structural equation modeling indicated that functional congruity of the physical environments and facilities were significantly and positively associated with delight, which in turn, affected air travelers' perceived well-being and satisfaction level in the lounge. It was also found that well-being perception significantly and positively affected brand identification and satisfaction, and loyalty was a positive and significant function of satisfaction. The mediation test showed that delight and well-being perception were significant mediators in the proposed theoretical framework. Practical and theoretical implications are discussed.heavy BSR infection pressure in ecofriendly manner.
\end{abstract}

Keyword: Traveler loyalty; Functional congruity; Delight; Well-being perception; Airport lounge 